\title{
PEMANFAATAN FREKUENSI ALAMIAH TANAH MENGGUNAKAN PENGUKURAN MIKROTREMOR TIGA KOMPONEN DALAM MENDETEKSI KEDALAMAN BATUAN DASAR
}

\author{
Erfan Syamsuddin ${ }^{1 *}$, Aulia Puji Astuti ${ }^{1}$, Sofian ${ }^{2}$, Dede Muhaimin Aziz ${ }^{1}$, Muhammad \\ Habibullah ${ }^{1}$, Sindy Yustin Linggi ${ }^{1}$ \\ ${ }^{1}$ Departemen Geofisika, Fakultas MIPA, Universitas Hasanuddin, Makassar, Indonesia \\ ${ }^{2}$ Stasiun Geofisika Kelas I Palu, Indonesia \\ *Corresponding author. Email: erfan.syamsuddin@unhas.ac.id
}

Manuscript received: 11 August 2021; Received in revised form: 24 September 2021; Accepted: 15 October 2021

\begin{abstract}
Abstrak
Suatu wilayah yang memiliki kondisi geologi yang sama dapat memberikan respon yang berbeda terhadap efek getaran tanah, bergantung pada karakteristik batuan penyusun formasi di wilayah itu. Fenomena ini disebut site effect. Spektra ambient noise yang diperoleh dari pengukuran mikrotremor dapat digunakan untuk menentukan respon suatu site khususnya frekuensi dominan lapisan sedimen. Respon frekuensi ini berhubungan dengan ketebalan lapisan sedimen. Berdasarkan formasi geologinya, Kota Palu tersusun atas endapan aluvium berumur holosen yang menjadi sedimen penyusun paling muda di wilayah tersebut. Penelitian ini bertujuan untuk memperoleh estimasi ketebalan lapisan sedimen di tiga titik pengukuran mikrotremor dari nilai spektrum horizontal to vertical $(H / V)$ yang merempresentasi frekuensi dominan $\left(\mathrm{f}_{0}\right)$ serta kecepatan gelombang geser $(V s)$ lapisan sedimen. Hasil yang diperoleh memperlihatkan nilai frekuensi dominan tanah $\mathrm{f}_{0}<2.5 \mathrm{~Hz}$, hasil inversi kurva HVSR memperlihatkan variasi ketebalan sedimen (Vs $<750 \mathrm{~m} / \mathrm{s}$ ) antara $152-186 \mathrm{~m}$ yang mengindikasikan lapisan sedimen penyusunnya masuk dalam kategori tebal, sedangkan variasi nilai Vs30 berada antara rentang $291-381 \mathrm{~m} / \mathrm{s}$. Hasil penelitian ini dapat digunakan sebagai dasar acuan untuk tujuan geoteknik, seperti desain bangunan tahan gempabumi berdasarkan respon frekuensi dominan tanah serta kecepatan gelombang gesernya.
\end{abstract}

Kata Kunci: HVSR; mikrotremor; site effect.

\begin{abstract}
An area that has the same geological conditions can respond differently to the effects of ground vibrations, depending on the characteristics of the rock formations in that region. This phenomenon is called the site effect. Ambient noise spectra obtained from microtremor measurements can be used to determine the response of a site, especially the dominant frequency of the sediment layer. This frequency response is related to the thickness of the sediment layer. Based on its geological formation, Palu City is composed of alluvium deposits of Holocene age which are the youngest sedimentary constituents in the region. This study aims to obtain an estimate of the thickness of the sediment layer at three microtremor measurement locations from the horizontal to vertical $(H / V)$ spectrum that represents the dominant frequency $\left(\mathrm{f}_{0}\right)$ and the shear wave velocity $(\mathrm{Vs})$ of the sediment layer. The results obtained show the dominant frequency of sediment $\mathrm{f}_{0}<2.5 \mathrm{~Hz}$, the results of the inversion of the HVSR curve show variations in sediment thickness (Vs $<750 \mathrm{~m} / \mathrm{s}$ ) between $152-186 \mathrm{~m}$ which
\end{abstract}


indicates that the sedimentary layers that make up the composition are in the thick category, while the variation in the value of Vs30 is between range $291-381 \mathrm{~m} / \mathrm{s}$. The results of this study can be used as a reference basis for geotechnical purposes, such as the design of earthquake-resistant buildings based on the dominant frequency response of the sediment and the shear wave velocity.

Keywords: HVSR; microtremor; site effect.

\section{Pendahuluan}

Survei mikrotremor, banyak memberikan sumbangsih untuk tujuan mitigasi bencana, keperluan geoteknik, dan perencanaan tata kota (Syahruddin et al., 2014). Menurut Wibowo et al. (2018), suatu wilayah dengan kondisi geologi yang sama dapat memiliki respon yang berbeda terhadap efek getaran tanah. Hal ini bergantung pada sifat serta karakteristik batuan penyusun formasi di wilayah itu. Fenomena ini disebut site effect. Salah satu faktor yang menyebabkan terjadinya local site effect ketika suatu wilayah mengalami goncangan gempabumi adalah ketebalan lapisan sedimen pada daerah tersebut.

Spektra ambient noise yang diperoleh dari pengukuran mikrotremor dapat digunakan untuk menentukan respon suatu site khususnya frekuensi resonansi lapisan sedimen. Respon frekuensi ini berhubungan dengan ketebalan lapisan sedimen dan kecepatan gelombang geser (Vs) (Syahruddin et al., 2014). Hubungan tersebut dituangkan dalam formulasi yang dikembangkan oleh (Nakamura, 2000), yaitu:

$$
f_{0}=\frac{V_{s}}{4 h}
$$

dengan $\mathrm{f}_{0}$ adalah frekuensi dominan yang diperoleh dari puncak spektrum $H / V$, Vs adalah kecepatan gelombang geser pada lapisan sedimen dan $H$ adalah ketebalan dari lapisan sediemen. Oleh karena itu, respon frekuensi dominan yang diperoleh dapat digunakan untuk tujuan geoteknik, dalam hal ini estimasi ketebalan sedimen suatu wilayah.

Gempabumi M 7.4 yang diakibatkan oleh Sesar Palu-Koro (BMKG, 2018) pada
September 2018 di Kota Palu banyak membawa pengaruh signifikan terhadap kerusakan infrastruktur di wilayah ini. Hal tersebut tidak lepas dari kondisi geologi lokal Kota Palu, yakni batuan penyusun yang mendominasi wilayah tersebut. Dikutip dari (Badan Geologi, 2018) material penyusun utama wilayah Kota Palu terdiri atas aluvial dan endapan pantai berumur holosen yang terdiri atas pasir, lanau, kerikil dan kerakal yang memiliki ukuran material yang tidak seragam, dengan lingkungan pengendapan delta, sungai dan laut dangkal, dan dianggap sebagai sedimen termuda pada wilayah ini. Sebaran endapan aluvial ini dapat dilihat pada peta geologi berikut (Gambar 1).

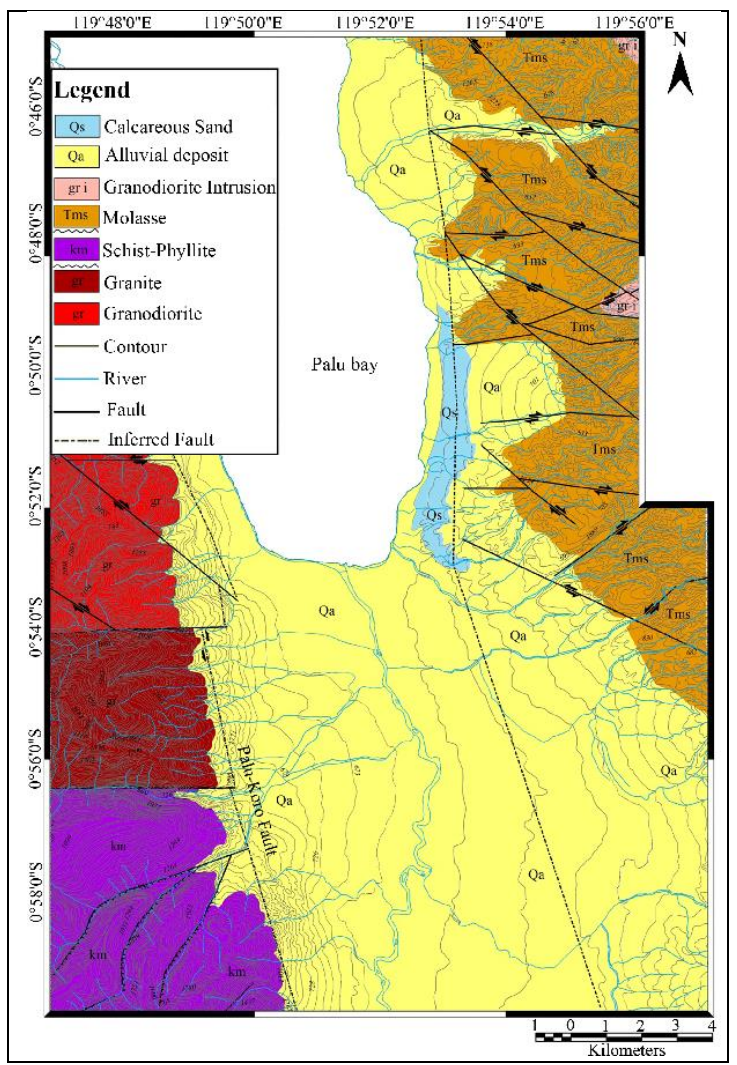

Gambar 1 Peta geologi yang memperlihatkan sebaran batuan penyusun wilayah Lembah Palu (Thein et al., 2014). 
Gelombang geser (Vs) terkait erat dengan modulus geser dan densitas batuan, sebagaimana direpresentasikan oleh persamaan berikut:

$$
V_{s}=\sqrt{\frac{\mu}{\rho}}
$$

dengan $\mu$ adalah modulus geser medium dan $\rho$ adalah densitas batuan. Persamaan tersebut mengindikasikan bahwa semakin besar nilai kecepatan gelombang geser, maka semakin besar pula nilai kekakuan tanahnya, yang mengidentifikasikan semakin keras dan padat lapisannya (Valeria et al., 2019).

Penelitian ini bertujuan untuk memperoleh estimasi ketebalan lapisan sedimen di tiga titik pengukuran mikrotremor dari nilai spektrum horizontal to vertical $(H / V)$ yang merepresentasikan frekuensi dominan lapisan sedimen serta kecepatan gelombang geser (Vs) dari hasil inversi kurva HVSR yang dapat digunakan untuk tujuan geoteknik kedepannya.

\section{Metode Penelitian}

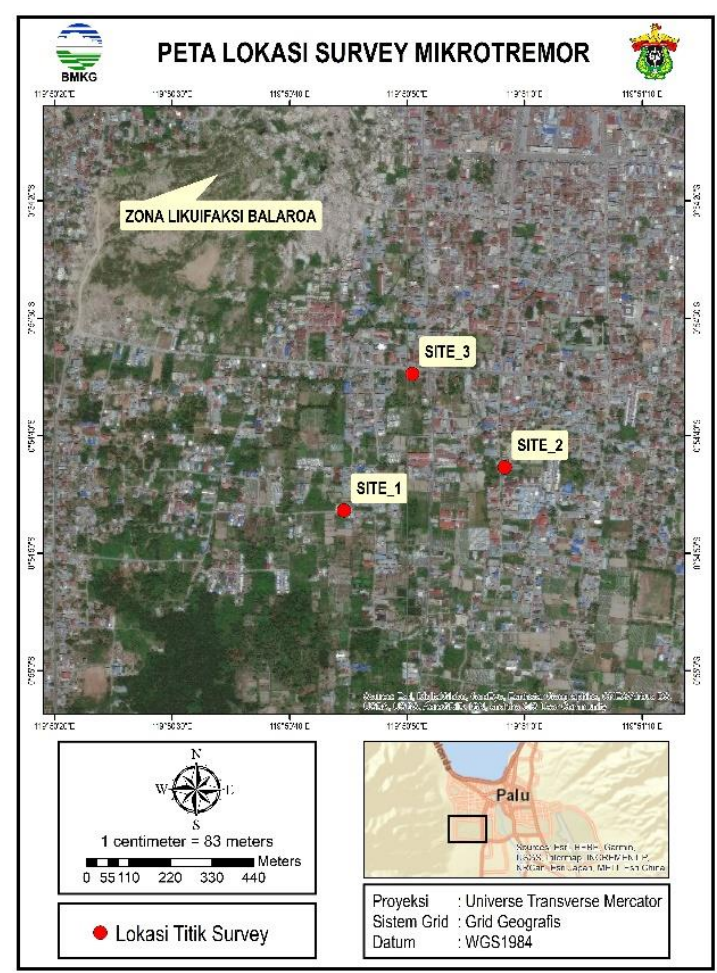

Gambar 2 Peta lokasi survey mikrotremor wilayah penelitian.
Penelitian ini menggunakan data mikrotremor pada tiga titik pengukuran di wilayah Palu Barat (Gambar 2). Akuisisi mikrotremor dilakukan menggunakan perangkat Portable Digital Seismograph TDS-303 dengan tipe sensor short-period DS-4A. Pengukuran mikrotremor dilakukan dengan durasi 45-60 menit sesuai standar operasional pengukuran oleh SESAME European Research Project (2004) dengan frekuensi sampling $100 \mathrm{~Hz}$.

Data mikrotremor yang diperoleh dalam domain time terdiri atas 3 komponen yakni vertikal (Up-Down) dan horizontal (EastWest dan North-South). Data rekaman dalam domain time tersebut diolah pada software Geopsy dengan menggunakan metode HVSR (Horizontal to Vertical Spectral Ratio) dengan terlebih dahulu dilakukan windowing dengan window length 10-50 s untuk menghilangkan sinyal yang bersumber dari efek transient selama pengukuran, yang dapat dilihat pada Gambar 3 berikut.

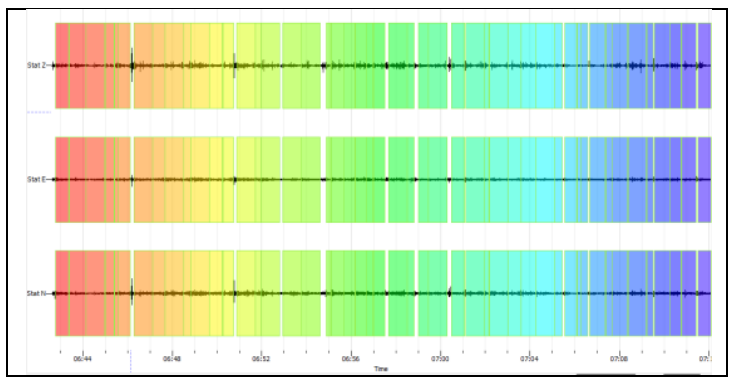

Gambar 3 Proses windowing sinyal untuk menghilangkan efek transient selama pengukuran.

Setiap warna dalam window tersebut memiliki rentang antara 10-50 s dan mewakili 1 frekuensi sinyal saat dilakukan FFT nantinya.

Selanjutnya dilakukan Fast Fourier Transform (FFT) pada setiap komponen untuk memperolah spektrum sinyal dalam domain frekuensi. Proses transformasi ini dirumuskan sebagai berikut:

$$
\begin{gathered}
X(f)=\int_{-\sim}^{\sim} x(t) e^{-j 2 \pi f t} d t \\
X(f)=\int_{-\sim}^{\sim} x(t) \cos (2 \pi f t) d t- \\
j \int_{-\sim}^{\sim} x(t) \sin (2 \pi f t) d t
\end{gathered}
$$

$\mathrm{X}(\mathrm{f})$ adalah fungsi sinyal dalam domain frekuensi, $x(t)$ adalah fungsi sinyal dalam 
domain waktu $-j 2 \pi f t$ adalah fungsi kernel, dan f adalah frekuensi (Riantana et al., 2019).

Dua sinyal komponen horizontal (NorthSouth dan East-West) dalam domain frekuensi digabungkan dengan kuadrat metode mean, seperti yang ditunjukkan pada persamaan berikut (Harsuko et al., 2020):

$$
A_{H}(f)=\sqrt{\frac{A_{N S}^{2}(f)+A_{E W}^{2}(f)}{2}}
$$

dengan $\mathrm{A}_{\mathrm{NS}}(\mathrm{f})$ dan $\mathrm{A}_{\mathrm{EW}}(\mathrm{f})$ adalah spektrum amplitudo komponen horizontal NorthSouth dan East-West, masing - masing. Setelah dua komponen horizontal digabungkan, perhitungan rasio komponen horizontal dan komponen vertikal $(H / V)$ dapat dihitung menggunakan persamaan (Harsuko et al., 2020):

$$
\operatorname{HVSR}(f)=\frac{A_{H}(f)}{A_{V}(f)}
$$

Selanjutnya dilakukan smoothing data menggunakan fungsi Konno \& Ohmachi dengan besar koefisien bandwidth 40 dan lebar 5\%, yang ditentukan oleh fungsi berikut:

$$
W b_{\left(f, f_{c}\right)}=\left(\frac{\sin \left(b \log _{10}\left(\frac{f}{f_{c}}\right)\right.}{b \log _{10}\left(\frac{f}{f_{c}}\right)}\right)^{4}
$$

dengan $\mathrm{f}$ adalah frekuensi, fc adalah frekuensi sentral tempat smoothing dilakukan, b adalah koefisien bandwidth (Konno \& Ohmachi, 1998).

Setelah diperoleh kurva HVSR, selanjutnya dilakukan inversi untuk memperoleh profil kecepatan gelombang geser (Vs) pada setiap titik pengukuran. Proses inversi ini menggunakan sofware max2curve dan dinver. Digunakan teknik HVTFA (Horizontal to Vertical Time-Frequency Analysis) yang menggunakan Continuous Wavelet Transform untuk mengidentifikasi gelombang P-SV dan meminimalkan efek dari gelombang love dan gelombang body yang dinyatakan dalam persamaan berikut (Atashband \& Esfanizadeh, 2012):

$$
C W T_{\{x\}(a, b)}=\frac{1}{\sqrt{|a|}} \int_{-\sim}^{\sim} x(t) \Psi *\left(\frac{t-b}{a}\right) \cdot d t
$$

dengan parameter a adalah parameter dilatasi dan $b$ adalah parameter translasi.

Selain dibutuhkan nilai dari spektrum $H / V$ dalam inversi kurva HVSR, juga dibutuhkan beberapa parameter fisis lain seperti Vp, Vs, poisson's ratio, dan rock density (Sunardi et al., 2018). Menurut Hakim et al. (2019), parameter input (Vp, Vs, poisson's ratio, dan rock density) tersebut berpengaruh dalam proses iterasi pencocokan kurva atau pendekatan model dengan kondisi aktual.

Inversi didasarkan pada algoritma Neighborhood (Sambridge, 1999) untuk mencari misfit minimum. Dari model awal ini, perhitungan misfit yang bersesuaian dilakukan menggunakan persamaan (Sunardi et al., 2018):

$$
\text { misfit }=\sqrt{\frac{1}{N} \cdot \sum_{i=1}^{N}\left(\frac{D_{i}-M_{i}}{\sigma_{i}}\right)^{2}}
$$

dengan $N$ adalah jumlah titik data, $D i$ adalah data hasil inversi, $M i$ adalah model struktur tanah, dan $\sigma_{\mathrm{i}}$ merupakan standar deviasi dari data hasil inversi dengan $1 \leq i \leq N$. Jika nilai misfit yang dihasilkan masih tinggi (>1) maka perlu dilakukan perubahan pada parameter model awal. Pada akhirnya, misfit dengan nilai terendah $(0 \leq$ misfit $<1)$ akan digunakan sebagai model terbaik (Sunardi et al., 2018).

Nilai dari kecepatan gelombang geser (Vs) hasil inversi di atas, dapat digunakan untuk perhitungan nilai Vs30 pada masing masing titik pengukuran, dengan menggunakan persamaan (Rusydi et al., 2018):

$$
V s_{30}=\frac{30}{\sum_{i=1}^{N}\left(\frac{h_{i}}{v_{i}}\right)}
$$

dengan, $h_{i}$ adalah ketebalan lapisan sedimen $(\mathrm{m}), \quad v_{i}$ adalah kecepatan gelombang geser $(\mathrm{m} / \mathrm{s})$ dan $\mathrm{N}$ adalah jumlah lapisan di atas kedalaman $30 \mathrm{~m}$. Nilai Vs30 dari pengukuran mikrotremor 
tersebut digunakan untuk menentukan karakteristik jenis tanah di masing - masing titik pengukuran hingga kedalaman 30 meter.

Setelah diperoleh nilai $\mathrm{Vs}$ dan $\mathrm{f}_{0}$, maka estimasi ketebalan sedimen dapat dihitung berdasarkan rumusan yang dikemukakan oleh (Nakamura, 2000), yakni:

$$
h=\frac{V_{s}}{4 f_{0}}
$$

dengan $\mathrm{h}$ adalah kedalaman lapisan sedimen, Vs adalah kecepatan gelombang geser dalam $\mathrm{m} / \mathrm{s}$ dan $\mathrm{f}_{0}$ adalah frekuensi dominan dari lapisan sedimen.

\section{Hasil dan Pembahasan}

$\begin{array}{llr}\text { Pengolahan } & \text { data } & \text { mikrotremor } \\ \text { menggunakan } & \text { metode } & \text { HVSR } \\ \text { menghasilkan } & \text { parameter } & \text { frekuensi } \\ \text { dominan tanah } & \left(\mathrm{f}_{0}\right) \text { pada } & \text { komponen } \\ \text { horizontal kurva } & \text { dan faktor } & \text { amplifikasi } \\ \text { tanah (A) pada } & \text { komponen vertikal di } \\ \text { masing-masing site pengukuran. }\end{array}$

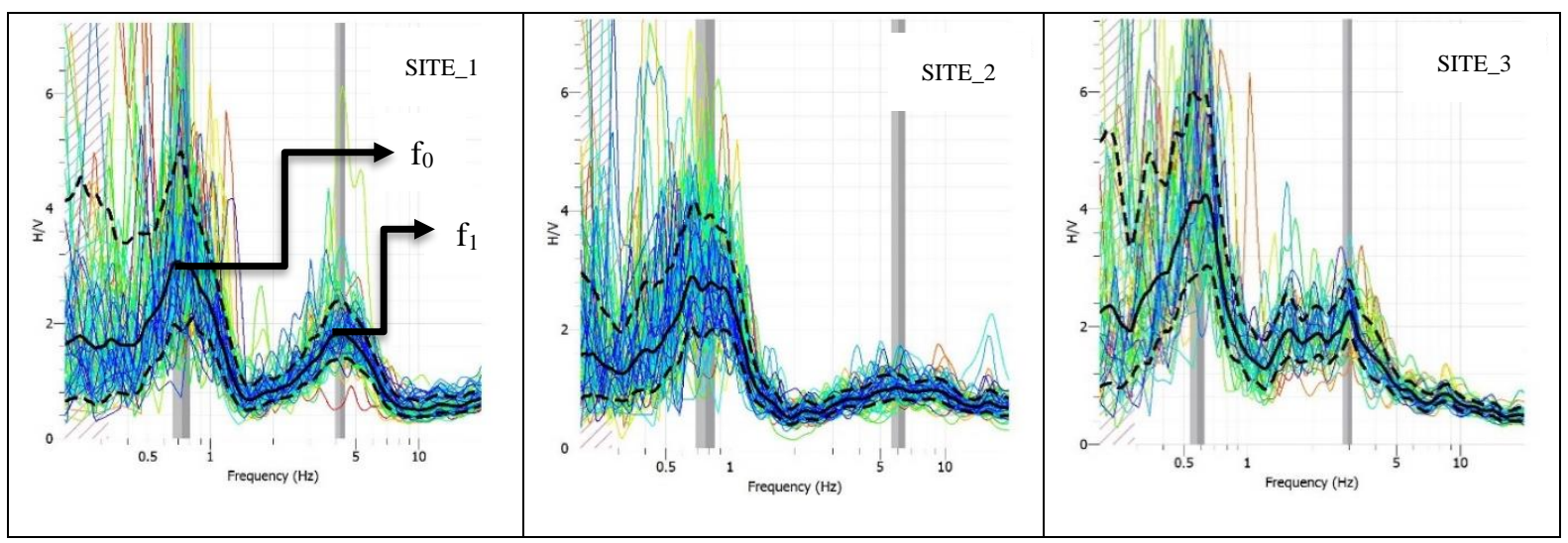

Gambar 4 Kurva HVSR pada ketiga site pengukuran, komponen horizontak merepresentasikan nilai frekuensi dominan $\left(\mathrm{f}_{0}\right)$ dan komponen vertikal merepresentasikan faktor amplifikasi tanah (A).

Hasil pengolahan data mikrotremor dalam penelitian ini menghasilkan kurva HVSR (Gambar 4) yang memperlihatkan adanya dua puncak frekuensi. Puncak pertama merepresentasikan frekuensi dominan $\left(\mathrm{f}_{0}\right)$ dari lapisan sedimen bawah permukaan (soil fundamental frequency), frekuensi dominan $\left(\mathrm{f}_{0}\right)$ yang lebih rendah ini mengindikasikan adanya kontras impedasi antar lapisan sedimen dengan lapisan batuan di bawahnya pada kedalaman yang besar. Sedangkan puncak kedua $\left(\mathrm{f}_{1}\right)$ (second peak) merepresentasikan adanya kontras impedansi antar lapisan sedimen pada kedalaman yang lebih dangkal. Nilai frekuensi dominan pada masing-masing site pengukuran dapat dilihat pada Tabel 1 .

Berdasarkan tabel tersebut, nilai frekuensi dominan $\left(\mathrm{f}_{0}\right)$ lapisan sedimen pada semua titik pengukuran menunjukkan nilai yang rendah yaitu $<2,5 \mathrm{~Hz}$. Berdasarkan klasifikasi oleh Kanai (1983), nilai frekuensi dominan tersebut merepresentasikan lapisan sedimen yang tersusun atas batuan aluvial, yang terbentuk dari proses sedimentasi delta dan top soil, dengan kedalaman $30 \mathrm{~m}$ atau lebih.

Tabel 1 nilai frekuensi dominan pada masingmasing site dari hasil analisa kurva HVSR.

\begin{tabular}{ccc}
\hline Kode Site & $\mathbf{f}_{\mathbf{0}}(\mathbf{H z})$ & $\mathbf{f}_{\mathbf{1}}(\mathbf{H z})$ \\
\hline SITE_1 & 0,745826 & 4,19563 \\
SITE_2 & 0,778735 & 6,08027 \\
SITE_3 & 0,580065 & 2,94072 \\
\hline
\end{tabular}

Sedangkan pada puncak kedua $\left(\mathrm{f}_{1}\right)$ yang merepresentasikan kontras impedansi pada lapisan sedimen yang lebih dangkal, memiliki rentang nilai 2,94 - 4,19 $\mathrm{Hz}$ yang mengindikasikan ketebalan sedimen permukannya masuk dalam kategori tebal, sekitar 10 - 30 meter, dan 6,08 Hz yang merepresentasikan ketebalan sedimennya 
masuk kedalam kategori menengah antara 5 $-10 \mathrm{~m}$.

Berdasarkan klasifikasi oleh Kanai (1983), karakteristik batuan pada rentang frekuensi tersebut berupa endapan alluvial. Hal ini sesuai dengan kondisi geologi wilayah Kota Palu (Gambar 1) yang didominasi oleh endapan aluvial.

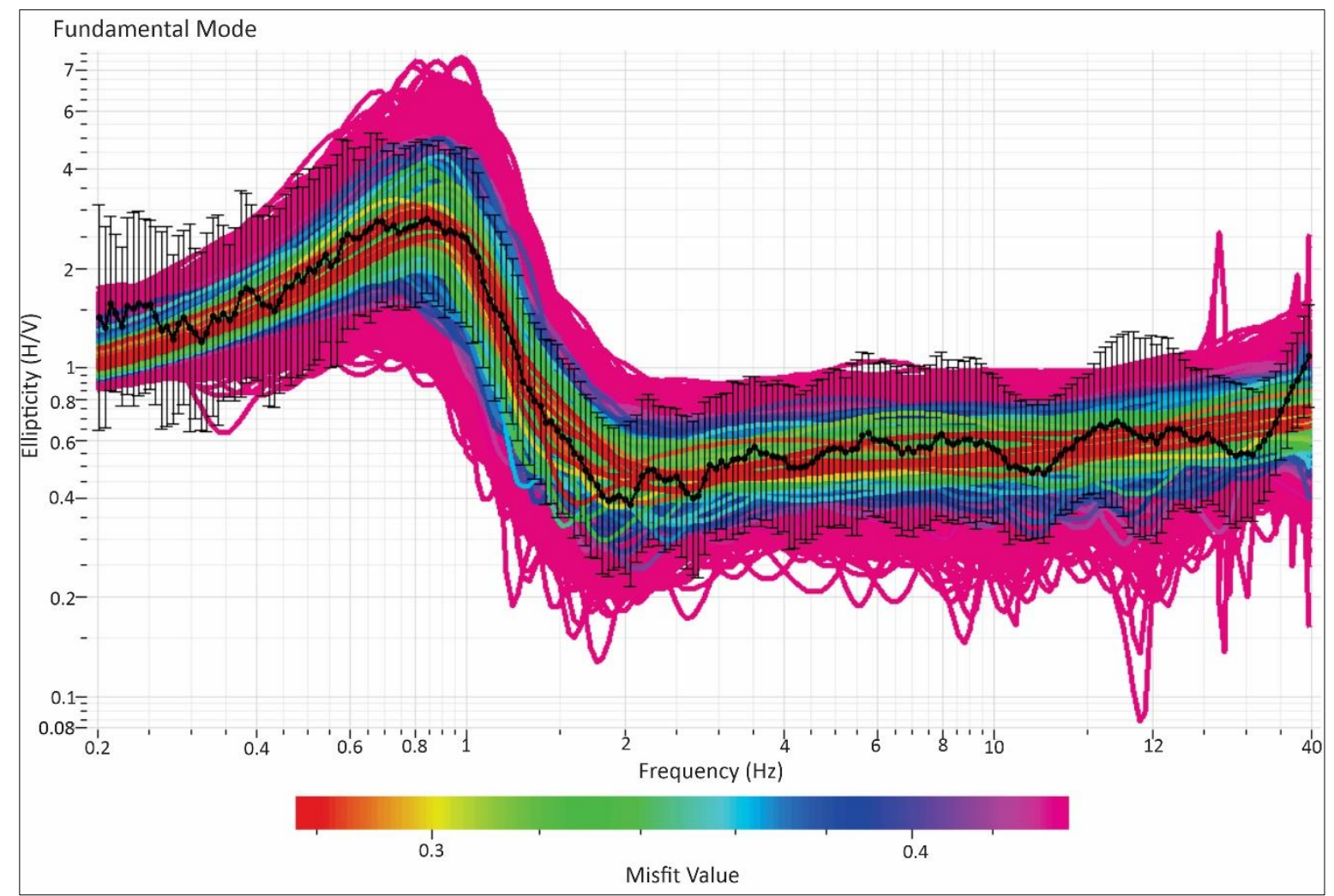

Gambar 5 Kurva eliptisitas hasil inversi menggunakan software dinver. Garis berwarna hitam merupakan kurva dari data obvervasi sedangkan garis berwarna lainnya merupakan model kalkukasi. Garis berwarna merah menunjukkan nilai misfit terkecil dan paling mendekati data observasi.

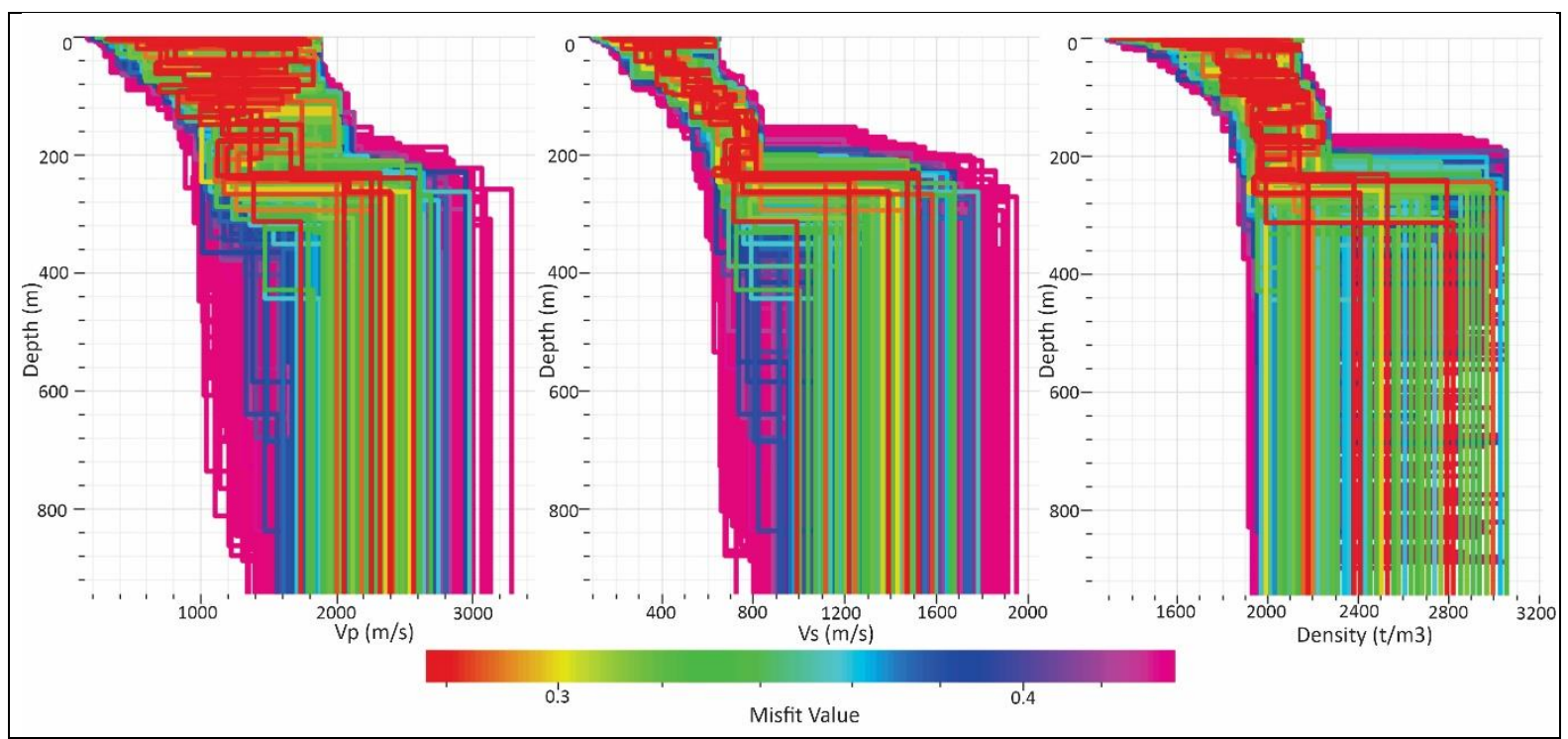

Gambar 6 Profil kecepatan gelombang primer (Vp), gelombang geser $(\mathrm{Vs})$ dan densitas batuan hasil inversi menggunakan software dinver.

Gelombang permukaan mendominasi data mikrotremor dan bentuk kurva $H / V$ sebagian besar didominasi oleh eliptisitas gelombang Rayleigh (P-SV) (Sunardi et al., 
2018). Gelombang permukaan banyak dimanfaatkan untuk karakterisasi site dalam geoteknik karena dapat mencitrakan struktur bawah permukaan dengan memanfaatkan sifat dispersi gelombang Rayleigh setiap kali merambat melewati batas lapisan bawah permukaan (Valeria et al., 2019). Oleh karena itu, dilakukan inversi kurva HVSR untuk mengidentifikasi gelombang Rayleigh (PSV). Hasil yang diperoleh dari inversi kurva HVSR ini adalah profil kecepatan gelombang geser (Vs) terhadap kedalaman yang dapat dilihat pada Gambar 5 dan 6.

Hasil inversi kurva eliptisitas menghasilkan parameter ground profile berupa $\mathrm{Vp}(\mathrm{m} / \mathrm{s})$, Vs $(\mathrm{m} / \mathrm{s})$, dan rock density terhadap kedalaman. Pada penelitian ini, hanya digunakan kecepatan gelombang geser (Vs) untuk karakterisasi site dengan mengekstraksi 10 nilai profil kedalaman dengan misfit terkecil, kemudian dimodelkan menggunakan ms.excel.

Garis berwarna coklat dari grafik dibawah menunjukkan 10 profil Vs dengan misfit terkecil, sedangkan garis berwarna hitam merupakan Vs rata-ratanya. Perhitungan nilai Vs30 pada Gambar 7 yang didasari pada Persamaan 10.

Berdasarkan profil kecepatan gelombang geser (Vs) terhadap kedalaman pada Gambar 7, diperoleh ketebalan lapisan sedimen dengan $\mathrm{Vs}<750 \mathrm{~m} / \mathrm{s}$ yang disajikan pada Tabel 2, hal ini didasarkan pada aturan SNI 1726:2012 yang mengasumsikan batuan dasar memiliki Vs $\geq 750 \mathrm{~m} / \mathrm{s}$.

Rentang nilai Vs30 yang diperoleh pada setiap site dalam penelitian ini berkisar antara 381 - $389 \mathrm{~m} / \mathrm{s}$, berdasarkan SNI (1726:2012), rentang nilai tersebut masuk kedalam kelas situs C yaitu hard soil, sedangkan Vs30 dengan nilai $291 \mathrm{~m} / \mathrm{s}$ termasuk dalam kelas situs D yakni medium soil. Nilai tersebut dipengaruhi oleh kondisi lapisan sedimen di wilayah penelitian yang sebagian besar tersusun atas endapan aluvium.

Tabel 2 Ketebalan lapisan sedimen berdasarkan nilai kecepatan gelombang geser $(\mathrm{Vs}<750 \mathrm{~m} / \mathrm{s}$ ) hasil inversi di masing-masing site pengukuran.

\begin{tabular}{cc}
\hline Kode Site & Ketebalan Sedimen $(\mathbf{m})$ \\
\hline SITE_1 & 186 \\
SITE_2 & 153 \\
SITE_3 & 152 \\
\hline
\end{tabular}

Sedangkan nilai Vs30 dari hasil inversi adalah sebagai berikut:

Tabel 3 Nilai Vs30 hasil inversi kurva HVSR

\begin{tabular}{cc}
\hline Kode Site & Vs30 $(\mathbf{m} / \mathbf{s})$ \\
\hline SITE_1 & 381 \\
SITE_2 & 389 \\
SITE_3 & 291 \\
\hline
\end{tabular}

Pramono et al (2017) menyebutkan bahwa wilayah Palu memiliki sebaran Vs30 yang relatif lebih rendah dibandingkan wilayah lainnya dengan rata-rata Vs30 lebih dari $200 \mathrm{~m} / \mathrm{s}$. Sedangkan Rusydi et al (2018) menyebutkan wilayah Palu khususnya di bagian barat yang mencakup wilayah penelitian ini, memiliki nilai Vs30 berdasarkan pengukuran mikrotremor berkisar $200-600 \mathrm{~m} / \mathrm{s}$.

Berdasarkan nilai Vs30 tersebut, dapat dihitung kedalaman lapisan sedimen yang memiliki kontras impedansi yang besar terhadap lapisan sedimen di bawahnya pada kedalaman yang lebih dangkal yaitu di atas $30 \mathrm{~m}$. Dalam hal ini tanah keras, untuk tujuan geoteknik seperti desain standar bangunan tahan gempabumi, hal ini ditandai dengan second peak pada Gambar 3. Kedalaman tanah keras tersebut diperoleh berdasarkan Persamaan 1, yaitu:

$h_{S I T E_{1}}=\frac{V_{S 30}}{4 f_{1}}=\frac{381}{4 \times 4,19563}=22,72 \mathrm{~m}$

Tabel 4 Estimasi kedalaman tanah keras pada kontras impedansi di frekuensi tinggi $\left(\mathrm{f}_{1}\right)$.

\begin{tabular}{cc}
\hline Kode Site & Kedalaman Tanah Keras $(\mathbf{m})$ \\
\hline SITE_1 & 22,72 \\
SITE_2 & 15,98 \\
SITE_3 & 24,72 \\
\hline
\end{tabular}



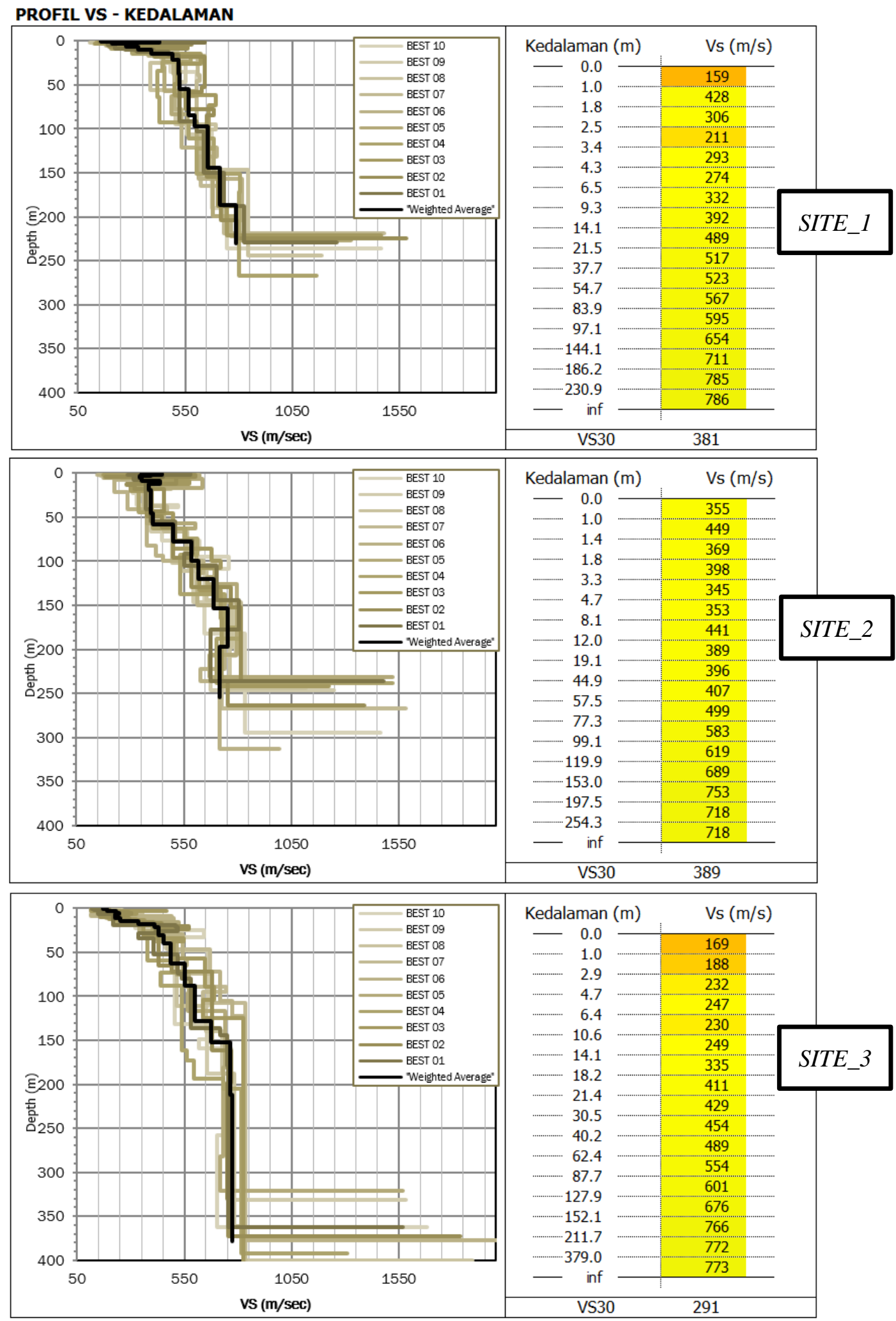

Gambar 7 Profil kecepatan gelombang geser (Vs) terhadap kedalaman dari hasil inversi kurva HVSR di masing-masing site pengukuran.

\section{Kesimpulan}

Berdasarkan penelitian yang telah dilakukan, dapat disimpulkan bahwa nilai frekuensi dominan tanah $\left(\mathrm{f}_{0}\right)$ di wilayah penelitian memiliki nilai yang rendah. Hal tersebut mengindikasikan bahwa ketebalan lapisan sedimen bawah permukaan di 
wilayah ini memiliki ketebalan yang besar. Dibuktikan dari hasil inversi kurva HVSR pada ketiga site pengukuran, diperoleh ketebalan lapisan sedimen masing-masing $186 \mathrm{~m}, 153 \mathrm{~m}$, dan $152 \mathrm{~m}$. Nilai frekuensi dominan $\left(\mathrm{f}_{0}\right)$ yang rendah mengindikasikan bahwa wilayah penelitian merupakan wilayah yang rentan terhadap gempabumi, karena $f_{0}$ yang rendah ini merepresentasikan lapisan batuan yang lunak. Tanah atau batuan yang lunak akan memiliki periode dominan getaran yang panjang dengan frekuensi rendah, begitupula sebaliknya. Hal ini akan mempengaruhi nilai amplifikasi tanah menjadi besar sehingga akan memiliki potensi kerusakan bangunan yang lebih tinggi di daerah tersebut ketika terjadi gempabumi.

Selain itu, nilai Vs30 yang diperoleh dari hasil inversi kurva HVSR menunjukkan klasifikasi tanah yang termasuk kedalam kategori tipe C (hard soil) dan D (medium soil) dengan estimasi kedalaman tanah keras di atas $30 \mathrm{~m}$ untuk keperluan geoteknik pada masing-masing site berkisar antara $22.72 \mathrm{~m}, 15.98 \mathrm{~m}$, dan $24.72 \mathrm{~m}$. Estimasi ketebalan sedimen untuk tujuan geoteknik di wilayah Kota Palu menjadi hal yang penting dikarenakan wilayah ini dilalui oleh Sesar Palu-Koro sehingga rancangan bangunan harus memperhatikan kondisi geologi bawah permukaan. Investigasi geoteknik melalui analisa mikrotremor dapat menjadi survei awal dalam menentukan zona yang rawan terhadap gempabumi berdasarkan respon frekuensi dominan tanah.

\section{Ucapan Terima Kasih}

Penulis mengucapkan terimakasih kepada LP2M Universitas Hasanuddin yang telah membantu penyelenggaraan penelitian ini. Juga kepada segenap pihak dari Stasiun Geofisika Kelas I Palu yang berperan banyak dalam proses akuisisi serta pengolahan data, kepada Departemen Geofisika Unhas, serta seluruh pihak yang telah memberikan saran yang membangun dalam penelitian ini.

\section{Daftar Pustaka}

Atashband, S., and Esfanizadeh, M. 2012. Effects Evaluation of Ambient Vibration Recording Conditions on HVTFA Results. In Proceedings of the 15th World Conference on Earthquake Engineering.

Badan Geologi. 2018. Di Balik Pesona Palu. Kementerian Energi dan Sumber Daya Mineral.

BMKG. 2018. Ulasan Guncangan Tanah Akibat Gempabumi Donggala 28 September 2018.

Hakim, A.C., Pramono, S., Warnana, D.D., Rochman, J.P.G.N., and Rahmatullah, F.S. 2019. Determination of Ground Profile and Peak Surface Acceleration (PSA) using single station microtremor Inversion method for earthquake hazard zonation of Lombok Island. IOP Conf. Series: Earth and Environmental Science. 389. https://doi.org/10.1088/17551315/389/1/012045

Harsuko, M.R.C., Zulfakriza, Nugraha, A.D., Sarjan, A.F.N., Widiyantoro, S., Rosalia, S., Puspito, N.T., and Sahara, D.P. 2020. Investigation of Hilbert Huang Transform and Fourier Transform for Investigation of Hilbert - Huang Transform and Fourier Transform for Horizontal-to-Vertical Spectral Ratio Analysis: Understanding the Shallow Structure in Mataram City, Lombok, Indon. Frontiers in Earth Science. 8(334). https://doi.org/10.3389/feart.2020.003 $\underline{34}$.

Kanai, K. 1983. Engineering Seismology. Tokyo: University of Tokyo Press.

Konno, K., and Ohmachi, T. 1998. GroundMotion Characteristics Estimated from Spectral Ratio between Horizontal and Vertical Components of Microtremor. Bulletin of the Seismological Society of America. 
88(1), $\quad$ pp.228 $\quad-\quad 241$. https://doi.org/10.1785/BSSA088001 $\underline{0228}$

Nakamura, Y. 2000. Clear identification of fundamental idea of Nakamura's technique and its applications. In: Proceedings of the 12th World Conference on Earthquake Engineering, 2656. http://www.sdr.co.jp/papers/n_tech_a nd_application.pdf

Pramono, S., Prakoso, W.A., Cummins, P., Rahayu, A., Rudyanto, A., Syukur, F., and Sofian. 2017. Investigation of subsurface characteristics by using a $V s 30$ parameter and a combination of the HVSR and SPAC methods for microtremor arrays. International Journal of Technology. 8(6), 983-992. https://doi.org/10.14716/ijtech.v8i6.6 $\underline{82}$

Riantana, R., Darsono., and Triyono, A. 2019. Design of Microtremor Monitoring Tools Using Accelerometer Sensor on Android Mobile to Determine the Natural Building Frequency in UNS Library. Journal of Physics: Conf. Series. 1204. https://doi.org/10.1088/17426596/1204/1/012103

Rusydi, M., Efendi, R., Sandra., and Rahmawati. 2018. Earthquake Hazard Analysis Use Vs30 Data in Palu. Journal of Physics: Conference Series. 979. https://doi.org/10.1088/17426596/979/1/012054

Sambridge, M. 1999. Geophysical inversion with a neighbourhood algorithm - I. Searching a parameter space. Geophys. J. Int. 138, pp. $479-$ 494. https://doi.org/10.1046/j.1365246X.1999.00876.x

SESAME. 2004. Guidelines For the Implementation of the $H / V$ Spectral Ratio Technique on Ambient Vibrations Measurements, Processing and Interpretation. SESAME European research project.

Sunardi, B., Naimah, S., Haryoko, U., Rohadi, S., Sulastri., and Rasmid.
2018. Vs30 Mapping and Soil Classification in the Southern Part of Kulon Progo Using Rayleigh Wave Ellipticity Inversion. Journal of Geospatial Information Science and Engineering. 1(2), 58-64. https://doi.org/10.22146/jgise.39780

Syahruddin, M. H., Aswad, S., Palullungan, E.F., Maria, \& Syamsuddin. 2014. Penentuan Profil Ketebalan Sedimen Lintas Kota Makassar Dengan Mikrotremor. Jurnal Fisika. 4(1), pp.17-25.

https://journal.unnes.ac.id/nju/index.p $\mathrm{hp} / \mathrm{jf} /$ article/view/3861

Thein, P.S., Pramumijoyo, S., Brotopuspito, K.S., Kiyono, J., Wilopo, W., Furukawa, A., and Setianto, A. 2014. Estimation of seismic ground motion and shaking parameters based on microtremor measurements at Palu city, Central Sulawesi province, Indonesia. International Journal of Geological and Environmental Engineering. 8(5), pp.308-319.

https://doi.org/10.5281/zenodo.10929 $\underline{38}$

Valeria, R., Rustadi, Zaenudin, A., and Sulaeman, C. 2019. Karakteristik Tanah di Daerah Cekungan Bandung Berdasarkan Kecepatan Gelombang Geser (Vs30) dengan Metode MASW (Multichannel Analysis of Surface Wave). Jurnal Geofisika Eksplorasi. 3(1), pp.57-70.

http://journal.eng.unila.ac.id/index.ph p/geo/article/view/1031

Wibowo, N.B., Sembri, J.N., Darmawan, D., Sumardi, Y., Afriliani, F., and Mahmudah, S. 2018. Intepretasi Lapisan Sedimen berdasarkan Ground Profile Vs dengan Pengukuran Mikrotremor di Kecamatan Pacitan. Indonesian Journal of Applied Physics. 8(1), pp.32-42. https://doi.org/10.13057/ijap.v8i1.149 $\underline{86}$ 